\title{
Fibrinogen Catabolism Study of Three Patients with Bacterial Endocarditis and Renal Disease
}

\author{
E. N. WARDLE, M. FLOYD
}

British Medical fournal, 1973, 3, 255-257

\section{Summary}

Three patients with bacterial endocarditis who developed renal failure have been studied by means of a radiofibrinogen catabolism study. Two were studied at the time of bacteraemia and one during the subsequent "immunological phase" of circulating immune complexes. Accelerated fibrinogen catabolism was found in all cases. Intravascular coagulation may be an important factor in the pathogenesis of proliferative glomerulonephritis in such cases.

\section{Introduction}

The occurrence of intravascular coagulation as a result of bacteraemia or septicaemia has been recognized at necropsy for many years (Hjort and Rapaport, 1965; Yoshikawa et al., 1971) but more recently by functional investigations such as detection of thrombocytopenia in association with raised fibrin degradation products (FDP) and coagulation factor depletion (Brodsky et al., 1968; Corrigan et al., 1968), and by radiofibrinogen catabolism studies (Rubenberg et al., 1967; Wardle, 1972 a). Evidence for general or localized intravascular coagulation in the course of bacterial endocarditis could be relevant to the subsequent finding of renal disease in such patients.

We report three cases of bacterial endocarditis studied by means of radiofibrinogen catabolism as illustrations of this thesis.

\section{Case 1}

STAPHYLOCOCCAL ENDOCARDITIS, ENDARTERITIS, AND ACUTE RENAI FAILURE

A 43-year-old woman was transferred to the renal unit with acute renal failure. For four weeks she had felt tired and in the last week had developed shortness of breath, sweats, joint pains, and a pustular rash on the lower limbs. Swabs from these lesions grew Staphylococcus aureus. Meantime she became oliguric and on admission her blood urea was $300 \mathrm{mg} / 100 \mathrm{ml}$ and serum creatinine $8.3 \mathrm{mg} / 100 \mathrm{ml}$. Examination showed a pale, febrile woman with splinter haemorrhages, aortic incompetence, and a pericardial friction rub. Blood cultures grew Staph. aureus. She was treated as a case of bacterial endocarditis and by initial peritoneal dialysis and then haemodialysis. A pleural effusion was tapped on several occasions. Even when her fever resolved she continued for many weeks to have a persistent anaemia and raised erythrocyte sedimentation rate, such that the possibility of an underlying collagen disorder was considered and she then had a skin and renal biopsy. At this stage she had raised IgG and IgM immunoglobulins, and cold agglutinins positive at $1 / 80$ dilution, but negative antinuclear factor and rheumatoid factor tests.

Department of Medicine, Royal Victoria Infirmary, Newcastle upon Tyne NE1 4LP

E. N. WARDLE, M.B., M.R.C.P., Senior Registrar

M. FLOYD, M.B., M.R.C.P., Senior Registrar

The radiofibrinogen catabolism study was performed during the first week after admission when she was on peritoneal dialysis, and with her permission. Details of the procedure have been published (Wardle, 1973). The standard technique of MacFarlane (1963) has been used. The course of the study is shown in fig. 1, from which it will be seen that after equilibration of the labelled fibrinogen $75 \%$ remained in the intravascular compartment and decayed at an exponential rate with a half-life of only 27.5 hours, which corresponded to a fractional turnover rate of $80.5 \%$ of the intravascular fibrinogen pool per day. After effective treatment of her septicaemia the fibrinogen breakdown rate declined towards a more normal rate with a fractional turnover rate of $26 \%$ of the body fibrinogen pool. Normal values for the preparation in use gave a half-life of 95.3 hours, with $82.5 \%$ of the labelled fibrinogen remaining in the intravascular compartment and a fractional catabolic rate of $21.8 \%$ (Wardle, 1973). The initial serum FDP level taken at the time of her positive blood culture was very high at $640 \mu \mathrm{g} / \mathrm{ml}$ (normal less than 20), indicating that the high fibrinogen catabolic rate was associated with intravascular coagulation. The renal biopsy specimen taken at a later date showed no evidence of glomerulitis or arteritis but tubular atrophy together with interstitial fibrosis. There was also a most striking intimal fibrous thickening of the interlobular arterioles, typical of endarteritis, together with hyalinosis of the smaller vessels.

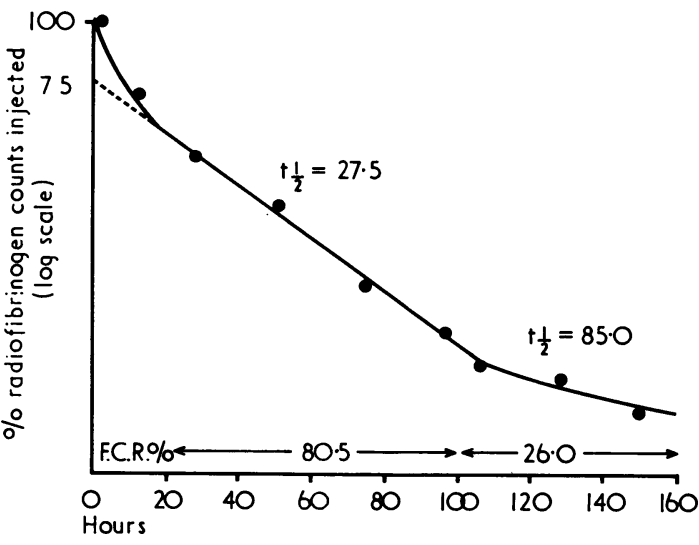

FIG. 1-Accelerated fibrinogen catabolism of bacteraemic phase of acute endocarditis and amelioration with treatment. F.C.R. = Fractional catabolic rate.

Case 2

SUBACUTE BACTERIAL ENDOCARDITIS, ACUTE RENAL FAILURE, AND AORTIC VALVE REPLACEMENT

A man of 45, previously a fit bricklayer, had weakened over one month and was found to have early clubbing together with aortic and mitral incompetence, and a blood culture grew Streptococcus viridans. His condition deteriorated and he developed acute renal insufficiency for which dialysis was required. It was at this stage that a renal biopsy was performed and the fibrinogen catabolism study was begun. The renal biopsy showed focal proliferative nephritis; the serum complement was low at $48 \mathrm{mg} / 100 \mathrm{ml}$. The initial half-life of the labelled fibrinogen was shortened to 65 hours corresponding to a fractional catabolic rate of $46.4 \%$ of the intravascular fibrinogen pool per day (fig. 2). At this stage he developed acute pulmonary oedema, and a diagnosis of acute destruction of the aortic valve was made, for which 


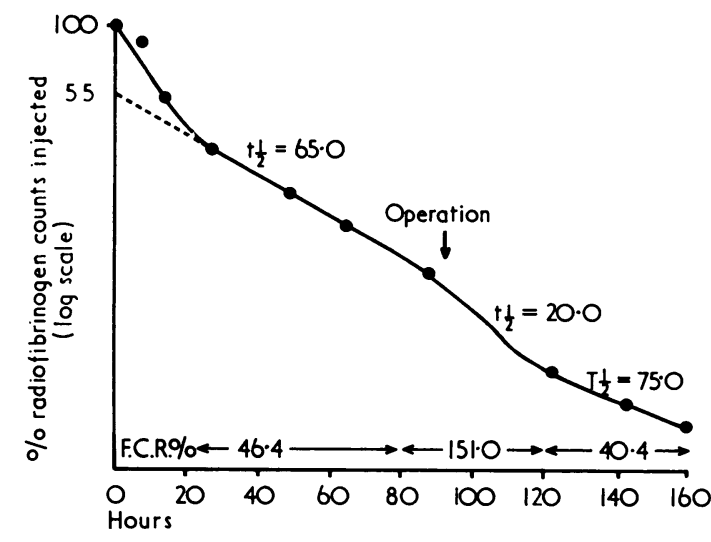

FIG. 2-Accelerated fibrinogen catabolism during subacute endocarditis, defibrination occurring at time of valve replacement, and subsequent improvement.

emergency replacement of the aortic valve was carried out. Some acute defibrination occurred during and after the operation but his fibrinogen catabolic rate then stabilized at a turnover rate of $40.4 \%$ per day. His progress was slow but one month later he was no longer in heart failure and his creatinine clearance had improved to $24 \mathrm{ml} / \mathrm{min}$. However, one week later he died of a subarachnoid haemorrhage due to rupture of a mycotic aneurysm. Renal histology showed subacute lobular glomerulonephritis with crescent formation.

\section{Case 3}

SUBACUTE ENDOCARDITIS CAUSING ADVANCED PROLIFERATIVE GLOMERULONEPHRITIS

A 45-year-old man, a civil servant, had felt tired and lethargic for four months when he was found to be anaemic and uraemic. Examination showed early clubbing, purpura on the arms, and a murmur of mitral incompetence. There were cotton-wool spots in the retinae and blood cultures grew non-haemolytic streptococci. He was therefore treated with penicillin and co-trimoxazole. Renal biopsy showed a rapidly progressive proliferative glomerulonephritis with crescent formation in all glomeruli, and also endocapillary proliferation. On account of his poor renal function, with a creatinine clearance of only $3 \mathrm{ml} / \mathrm{min}$, he had to have repeated peritoneal dialysis. His serum complement level remained persistently low at $20 \mathrm{mg} / 100 \mathrm{ml}$, and he received several blood transfusions for anaemia. In an attempt to improve his renal output he underwent a trial of heparinization for four days. During this time his renal function showed no evidence of improvement and his serum complement level also did not change. Cryoglobulins of mixed IgG-IgM type were detected in his serum. Therapy with penicillin was continued and by eight weeks after the start of treatment his creatinine clearance had risen to over $10 \mathrm{ml} / \mathrm{min}$. It was at this stage that he had his radiofibrinogen catabolism study (fig. 3). Cryoglobulins were still present in the serum, the serum complement was starting to rise, and he now had proteinuria to the extent of $1.5 \mathrm{~g} /$ day. The radiofibrinogen study performed therefore during the recovery phase showed an accelerated turnover of $35.0 \%$ of the intravascular fibrinogen pool per day, as indicated also by the shortened half-life of 70 hours. The details of the radiofibrinogen catabolism studies are summarized in the table. Normal values are taken from previous data (Wardle, 1973).

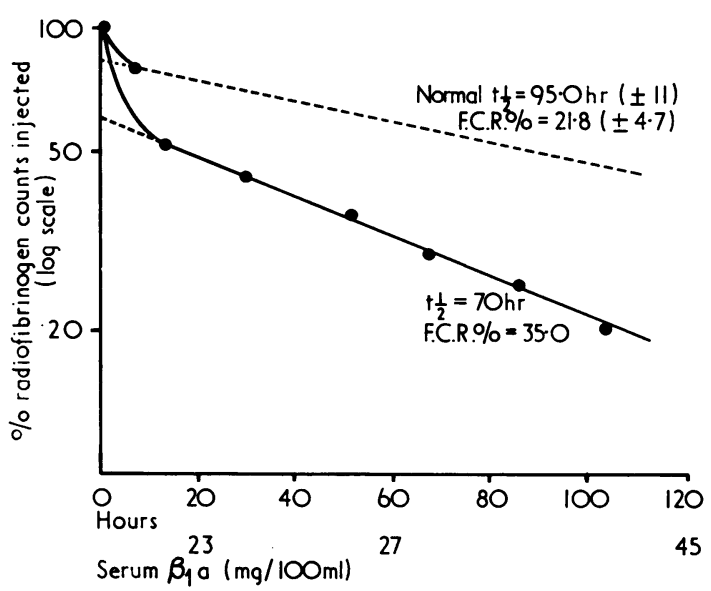

FIG. 3-Accelerated fibrinogen catabolism due to immunological phase of endocarditis.

\section{Discussion}

That bacterial endocarditis may cause either focal embolic nephritis or a diffuse proliferative lesion has been recognized for many years (Bell, 1932). Spain and King (1952) were able to show that effective antibiotic therapy prevented the diffuse lesion and reduced the incidence of the focal lesion. The recognition of the immune complex aetiology of nephritides has been more recent (Dixon, 1968) and has led to a search for and recognition of immune complexes in the kidneys of patients with endocarditis (Kaufman and McIntosh, 1971; Gutman et al., 1972). Indeed Cordeiro et al. (1965) presented their reasons for an "immunological phase" of endocarditis based on the appearance of rheumatoid factors, a lowering of serum complement, and a rise of immunoconglutinin. Similar studies made by Williams and Kunkel (1962) and Messner et al. (1968) showed a lowered serum complement which is a reflection of the presence in the circulation of immune complexes, many of which are detectable as cryoglobulins on account of their rheumatoid factor component and large size.

Intravascular coagulation is associated with bacteraemia (Gans and Krivit, 1961; Stehbens et al., 1969) because of the effect of endotoxin in causing platelet aggregation, endothelial cell damage, and fibrin formation. It also occurs when there are circulating immune complexes (Vassalli and McCluskey, 1971; Wardle, 1972 b) which initiate damage to platelets and possibly also activation of Hageman coagulation factor. Thus in endocarditis there are good reasons for suspecting a chronic state of intravascular coagulation, and this prediction has been substantiated by the results of the three cases reported here. Each showed pronounced acceleration of radiofibrinogen catabolism.

Proliferative glomerulonephritis with crescent formation, which was the feature in cases 2 and 3, is known to result in intraglomerular fibrin formation as a result of local intravascular coagulation (McCluskey et al., 1966). The large fraction of the cardiac output that passes through the kidneys is the probable explanation for the noticeable effect on radiofibrinogen catabolism, but enhanced fibrinogen removal by reticuloendothelial

Radiofibrinogen Catabolism Data

\begin{tabular}{|c|c|c|c|c|c|c|c|c|}
\hline & Case & & & Intravascular Fibrinogen & Radiofibrinogen Half-life & Fractional Catabolic Rate & Absolute Catabolic Rate & Serum FDP \\
\hline $\begin{array}{l}1 \\
2 \\
3\end{array}$ & $\because$ & $\because$ & $\ddot{0}$ & $\begin{array}{l}190 \\
170 \\
182\end{array}$ & $\begin{array}{l}27.5 \rightarrow 85 \cdot 0 \\
65 \cdot 0 \rightarrow 20 \cdot 0 \rightarrow 75 \cdot 0 \\
70 \cdot 0\end{array}$ & $\begin{array}{l}80.5 \rightarrow 26 \cdot 0 \\
46 \cdot 4 \rightarrow 151 \cdot 0 \rightarrow 40.4 \\
35 \cdot 0\end{array}$ & 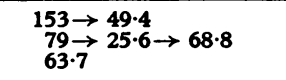 & $\begin{array}{r}640 \\
30 \\
24\end{array}$ \\
\hline Nor & I val & & .. & $100-300$ & $95.3 \pm 10.9$ & $21.8 \pm 4.7$ & $25-35 \cdot 0$ & $<10$ \\
\hline
\end{tabular}


activity (Regoeczi, 1970) may also occur. Additionally it seems that fibrin deposition on arteriolar walls as part of an immunological reaction can give rise to a chronic endarteritis, akin to that seen in chronic renal transplant rejection (Porter, 1967). The accelerated fibrinogen turnover in case 1 might indeed be seen as the cause of that patient's endarteritis. The occurrence of endarteritis in association with endocarditis has recently been stressed by Morel-Maroger et al. (1972). This type of lesion was recognized by Powell (1961) to occur as a result of staphylococcal septicaemia, in which condition a variety of renal lesions, from cortical necrosis to glomerulonephritis, are found. The production by staphylococci of the procoagulant coagulase is the explanation for the intravascular coagulation of staphylococcal septicaemia (Smith and Johnstone, 1958). Additionally at a later stage antibody production to the relevant antigen will result in immune complex formation in the circulation. Such circulating complexes will initiate damage to platelets (Wardle, 1972 b) and may well be responsible for a chronic low grade state of intravascular coagulation. It will occur particularly in the kidneys wherein complexes are concentrated by ultrafiltration. The process might well be perpetuated if antigen is continually accessible on the heart valves or if the patient starts to form antibodies to his own altered gammaglobulin, which is a plausible explanation for the development of rheumatoid factors. It would therefore be reasonable to associate a low serum complement, in the context of endocarditis, not only with the occurrence of immune complexes but also with intravascular coagulation. All three mechanisms could be contributory to the rapidly progressive proliferative glomerulonephritis, with crescent formation, that is often observed.

Case 2 shows that anticoagulation in this particular form of nephritis is best avoided, and case 3 shows that it may in any event be ineffective. Our own group (Wardle and Uldall, 1972), in common with others, have reported some benefit from heparinization in other forms of progressive glomerulonephritis, but that paper also notes the failure of heparin to affect the serum complement level. Case 3 again attests to this fact. Indeed the best hope for improvement in these cases lies still in classical therapy with early and large doses of antibiotics.

We are grateful to Professor D. N. S. Kerr for his support.

\section{References}

Bell, E. T. (1932). American fournal of Pathology, 8, 639.

Brodsky, I., Myer, A. N., Benham Kahn, S., and Ross, E. M. (1968). American fournal of Clinical Pathology, 50, 211.

Cordeiro, A., Costa, H., and Laginha, F. (1965). American fournal of Cardio$\log y, 16,477$.

Corrigan, J.' J., W Walker, L. R., and May, N. (1968). New England fournal of Medicine, 279, 850 .

Dixon, F. J. (1968). American fournal of Medicine, 44, 493.

Gans, H., and Krivit, W. (1961). Annals of Surgery, 153, 453.

Gutman, R. A., Striker, G. E., Gilliland, B. C., and Cutler, R. E. (1972). Medicine, 51 ,

Hjort, P. F., and Rapaport, S. I. (1965). Annual Review of Medicine, 16, 135. Kaufman, D. B., and McIntosh, R. (1971). American fournal of Medicine, 50,

McCluskey, R. T., Vassalli, P., Gloria, G., and Baldwin, D. S. (1966). New England Fournal of Medicine, 274, 696.

MacFarlane, A. S. (1963). Fournal of Clinical Investigation, 42, 346.

Messner, R. P., Laxdal, T., Quic, P. G., and Williams, R. C. (1968). Annals of Internal Medicine, 68, 746 . Morel-Maroger, L., Sraer, J. D., Herreman, G., and Godeau, P. (1972).
Archives of Pathology, 94, 205.

Porter, K. A. (1967). Fournal of Clinical Pathology, Suppl., No. 20, p. 518.

Powell, D. E. B. (1961). Fournal of Pathology and Bacteriology, 82, 141 .

Regoeczi, E. (1970). In Plasma Protein Metabolism, ed. M. A. Rothschild and T. Waldmann, chap. 30. New York, Academic Press.

Rubenberg, M. L., Baker, L. R. I., McBride, J. A., Sevitt, L. M., and Brain, M. C. (1967). British Medical Fournal, 4, 271.

Smith, D. E., and Johnstone, J. M. (1958). British fournal of Experimental Pathology, 39, 165

Spain, D. M., and King, D. W. (1952). Annals of Internal Medicine, 36, 1086. Stehbens, W. E., Sonnenwirth, A. C., and Kotrba, C. (1969). Experimental and Molecular Pathology, 10, 295 .

Vassalli, P., and McCluskey, R. T. (1971). In Advances in Nephrology, ed. J. Hamburger, J. Crosnier, and M. H. Maxwell, vol. 1, chapt. 4. Year Book Medical Publishers, Chicago.

Wardle, E. N. (1972 a). Scandinavian fournal of Infectious Diseases, 4, 155.

Wardle, E. N. (1972 b). Fournal of the Royal College of Physicians, 7, 5.

Wardle, E. N. (1973). Quarterly fournal of Medicine, 42, 205.

Wardle, E. N., and Uldall, P. R. (1972). British Medical fournal, 4, 135.

Williams, R. C., and Kunkel, H. G. (1962). Fournal of Clinical Investigation, 41, 666.

Yoshikawa, T., Tanaka, K. R., and Guze, L. B. (1971). Medicine, 50, 237.

\title{
Acute Intermittent Porphyria: Response of Tachycardia and Hypertension to Propranolol
}

\author{
A. D. BEATTIE, M. R. MOORE, A. GOLDBERG, R. L. WARD
}

British Medical fournal, 1973, 3, 257-260

\section{Summary}

In four young adult patients with acute attacks of acute intermittent porphyria tachycardia and hypertension were prominent features of the illness. Urinary catecholamine excretion was increased in both patients in whom it was measured. The effect of the beta-adrenergic blocking drug propranolol was assessed in each case. The dose varied from 40 to $240 \mathrm{mg}$ daily. A response in the form of a reduction in heart rate and blood pressure was noted

\footnotetext{
University Department of Materia Medica and M.R.C. Group in Iron and Porphyrin Metabolism, Stobhill General Hospital, Glasgow G21 3UW

A. D. BEATTIE, M.D., Honorary Registrar

M. R. MOORE, B.SC., PH.D., Research Biochemist

A. GOLDBERG, M.D., F.R.C.P., F.R.S.ED., Regius Professor of Materia Medica

Royal Infirmary, Blackburn, Lancashire

R. L. WARD, M.D., F.R.C.P., Consultant Physician
}

in each case, and in one case a marked alleviation of abdominal pain followed administration of the drug.

Propranolol, when given in high dosage to rats, did not induce an increase in hepatic delta-aminolaevulic acid synthetase, an enzyme which is raised in human and drug-induced animal porphyria. The use of propranolol is therefore unlikely to aggravate or precipitate an attack of acute intermittent porphyria.

\section{Introduction}

Acute intermittent porphyria is an inherited metabolic error in which delta-aminolaevulic acid (ALA) and porphobilinogen (PBG) are formed excessively in the liver. Clinically it is characterized by gastrointestinal symptoms and involvement of the nervous system. Tachycardia is present in most patients during an attack and is a good index of the activity of the disease (Waldenström, 1937; Goldberg, 1959). Hypertension in acute porphyria was first described by Melkersson (1925) and has subsequently been reported in about $50 \%$ of patients during an attack (Goldberg, 1959). Papilloedema, hypertensive encephalopathy, and left ventricular failure have all been described in 